\title{
The Short-Run and Long-Run Relationships between Mortality and the Business Cycle in Canada
}

\author{
Zuzana Janko, ${ }^{1}$ J. C. Herbert Emery, ${ }^{2}$ and Pierre Guenette ${ }^{2}$ \\ ${ }^{1}$ Department of Economics, San Francisco State University, 1600 Holloway Avenue, San Francisco, \\ CA 94132, USA \\ ${ }^{2}$ Department of Economics, University of Calgary, 2500 University Drive NW, Calgary, AB, Canada T2N 1N4
}

Correspondence should be addressed to Zuzana Janko; zjanko@sfsu.edu

Received 20 April 2013; Accepted 5 June 2013

Academic Editor: Colin C. Williams

Copyright (c) 2013 Zuzana Janko et al. This is an open access article distributed under the Creative Commons Attribution License, which permits unrestricted use, distribution, and reproduction in any medium, provided the original work is properly cited.

\begin{abstract}
This paper investigates the relationship between health and the business cycle for the Canadian economy. The majority of existing literature shows a procyclical relationship between death rates and indicators of the business cycle, suggesting that recessions are good for one's health. We use a time series error correction model to determine the short-run and long-run impacts of the unemployment rates on death rates. Our results indicate that temporary slowdowns in economic activity are associated with lower death rates. Moreover, once we stratify the data by sex, we find a long-run negative relationship between the unemployment rate and death rates for both sexes.
\end{abstract}

\section{Introduction}

In a series of influential works, Ruhm [1-4] provides strong evidence of a procyclical relationship between the business cycle and mortality, which suggests that recessions are good for a population's health. (In Ruhm [4] a one percentage point decrease in unemployment rate is predicted to increase heart attack mortality (AMI) by $1.3 \%$.) Ruhm's findings for the USA have been confirmed in studies for Germany [5], Spain [6], and Japan [7]. This relationship is also found in developing countries. Specifically, Khang et al. [8] find a positive relationship for South Korea, and Abdala et al. [9] find it for Argentina. The procyclicality of death has also been shown in panel studies of OECD and EU countries in Gerdtham and Ruhm [10] and McAvinchey [11], respectively.

Despite the large literature showing that temporary downturns in economic activity are good for one's health, Gerdtham and Johannesson [12] and Svensson [13] find a countercyclical relationship between mortality rates and the business cycle in Sweden. Hence, the procyclical relationship between mortality and the business cycle cannot be generalized to all countries.

In a 2011 paper, Arizumi and Schirle use Canadian data to assess the role of the business cycle on health. They use a time series model and largely confirm the results of Ruhm [1]. In this paper, we take a different approach from that of Arizumi and Schirle [14] in analyzing the relationship between the business cycle (via the unemployment rate) and mortality, at the aggregate level as well as by gender. First, we use an error correction model, which allows us to specifically assess the short-run and long-run impacts of unemployment rate on mortality. This approach implies that we can also quantify the speed of adjustment, thus determining how long after a rise in unemployment are mortality rates affected. Next, given our model, we make use of data available from 1950 onwards. (Arizumi and Schirle [14] use data from 1975 onwards. This is because they consider the impact on mortality by age; data is only available from 1975 (Statistics Canada only publically provides data from 1991 until now).) Lastly, we make sure to control for health expenditure per capita and income per capita in our model, as both have been increasing over time; no controls are utilized in Arizumi and Schirle [14].

Ruhm's work builds on an existing research, including the early work of Brenner [15], who followed the early documentation of a procyclical relationship between mortality and the business cycle by Ogburn and Thomas [16] and Thomas [17]. Brenner $[15,18,19]$ used post Great Depression aggregate times series data to show that slowdowns in economic activity 
were accompanied by increases in mortality rates, thus concluding that recessions are bad for one's health. Moreover, Brenner showed that deaths due to cardiovascular disease, suicide, homicide, infant mortality rates and admissions to mental hospitals rose during economic contractions. The reasons for this relationship Brenner argued could stem from the array of losses one is subject to during recessions, increases in stress, and the simultaneous social changes, all of which can potentially threaten health. However, his results were shortly subject to vast criticism in Gravelle et al. [20], Kasl [21], Stern [22], and Wagstaff [23], stemming primarily from Brenner's methodology. (Specifically, the choice of covariates and the method used to choose lag lengths have been critiqued. Moreover, the plausibility of the results has been questioned [24]. The epidemiologists argued that their findings and Ruhm's later were artifacts of aggregation (the ecological fallacy).) For example, Ruhm [1] argued that Brenner's study suffered from omitted variable bias as Brenner did not account for the vast improvements in nutrition and availability of antibiotics following the Great Depression.

Although much of recent academic research shows a positive relationship between the business cycle and death rate as discussed previously, the media coverage of the impact of recessions on population health tends to support both sides; thus the belief that recessions are bad for one's health continues to take center stage as do those to the contrary. (In 2009, TIME.com discussed the work of Ruhm and others in an article entitled "Could recessions be good for your health." Other articles presenting the positive effects of recessions on health are a 2009 article in the Globe and Mail by P. Taylor, among others.) In 2009, UK's The Telegraph ran an article entitled "The recession is bad for your health, experts warn" stating job losses as the key factor as argued by Danny Dorling, Professor of Human Geography at Sheffield University [25]; Sarnia Observer in Canada ran an article under a similar title the same year stressing the negative effects of recessions on health based on a survey showing a decrease in doctor visits and prescription refills [26]. More recently, in January 2013, Health.com had an article that reported on a survey conducted at the University of Maryland School of Public Health; the survey showed a fall in doctor visits and prescription refills, and so forth [27]. While informative, these articles and surveys are unable to conclude whether the observed patterns of decrease in health services resulted in more death. (The author of the Health.com article, S. Reinhart, presents this as well.) In addition, the articles tend to ignore positive effects of recessions on health-which in aggregate can dominate-likely due to the fact that positive effects are seen by many as "counterintuitive." (In the 2009 Globe and Mail article, Granados is quoted as saying "Most people assume that periods of recession are harmful to health.")

Ruhm [1] argues that there are at least four reasons why temporary upturns in economic activity are bad for one's health. For one, rising hours worked during expansions increase the opportunity cost of time; hence, individuals find it costly to take off work to attend medical appointments. Second, as working hours are extended during expansions hazardous working conditions, job-related stress, and physical effort in the labor force (particularly construction) can lead to lower health and rising mortality. Third, external risk factors for death can increase when times are good, such as drinking and driving. In line with Brenner's views, however, Ruhm, does acknowledge that suicide rates rise as economic conditions deteriorate. Lastly, according to Ruhm, migration to larger urban centers during an economic boom can lead to higher mortality due to an increase in drivers on the roads leading to more car accidents and rising stress levels.

In this paper, we conduct an aggregate time series analysis for Canada to determine the short-run and long-run impacts of economic downturns and upturns on mortality rates; hence, our objective is not to focus on any particular individual factor that impacts health but instead to analyze the effects of recessions on population health and health of males and females separately. We use an error correction model (ECM) of Hendry [28, 29] as in Laporte [30] who uses ECM to examine the same relationship for US data. The error correction model introduces past disequilibrium as an explanatory variable in the dynamic behavior of current variables. We start our analysis by analyzing the relationship at the aggregate level, controlling for per capita income and health expenditures. Our results support the argument made by Ruhm [1] that recessions are good for your health, in that we find that a $1 \%$ point increase in the unemployment rate lowers the death rate by approximately 7.4 per 100,000 which translates to around 2500 deaths avoided in a given year in Canada.

Once we stratify the data by gender, we find unemployment rates to have short-run and long-run impacts. Specifically, a rise in the unemployment rate by $1 \%$ point has an immediate impact of 6.5 per 100,000 fall in the death rate. In addition, there is a fall in the female death rate by approximately 8.5 per 100,000 over time, with $26.9 \%$ of the longrun adjustment in the death rate occurring next year and $98 \%$ of the adjustment occurring over ten years. This translates to approximately 2500 female deaths avoided over an eleven-year period given today's population trends. In contrast, the results for males indicate a fall of approximately 1500 deaths in the six years following a $1 \%$ point rise in unemployment a given year, as the rate of adjustment is faster with a total fall of male death rate of 9 per 100,000 in the long run. Overall, our results support the conjecture that recessions in Canada are good for one's health irrespective of gender. Hence, our results are important, as they indicate that while recessions are good for one's health, it is during periods of expansions that death rates rise. Consequently, while the public may believe that public policy interventions are needed during times of recessions to target health, our findings indicate that for Canada, periods of expansions are detrimental to health and should not be ignored. (Raj [26] states that "the federal government needs to focus more attention on health care" during times of recession.)

The paper is organized as follows. The data used are discussed in Section 2. In Section 3, we present our modeling strategy and discuss our results. First, we give the descriptive statistics, followed by the ECM results using aggregate unemployment and death rate, followed by gender specific ECM results. Section 4 concludes the paper. 


\section{Data Description}

We use annual Canadian data from 1950 to 2006. Our primary data sources are Statistics Canada's CANSIM II database and the Historical Statistics Canada, Second Edition; all data sources are provided in the appendix. First, we use the death rate per 1,000 individuals, considering both aggregate death rates as well as death rates for females and males separately. This measure of mortality rate is for all types of deaths, including accidental deaths, suicides, and heart attacks for all age groups. (Data availability by types of mortality rates is only from 1974 to present, while data by age group is only available from 1991 to present. Due to this limitation, we consider aggregate mortality rates in our analysis.) Next, following the practice in the literature as in Ruhm [1], Gerdtham and Johannesson [12], Gerdtham and Ruhm [10], Svensson [13], and Laporte [30], among others, we use the aggregate unemployment rate (15 years and older) as an indicator of the overall state of macroeconomic activity. Unemployment is commonly used to the fact that it is falling in expansions and rising in recessions. For example, in Canada, unemployment peaked to $12 \%$ and $11 \%$ during the 1982 and $1990-91$ recessions, falling to $7.5 \%$ and $6.5 \%$ on average in the subsequent nonrecessionary periods, respectively.

As in Laporte [30], we use per capita gross domestic product (GDP) in 1992 constant dollars in our models to control for income. (We spliced a GNP series with a GDP series, as GDP in Canada is available from 1975. Norrie et al. [31] find that GNP since 1947 is typically $97 \%$ of the value of GDP. To obtain real per capita values, we use the consumer price index and total population data.) In addition, following real total health expenditure per capita, consisting of the total nominal expenditures on health services (hospitals, doctors, prescriptions, etc.) by the public and the private sector, is added to the model to control for the impact of rises in medical services, as these can be argued to improve an individual's health and thus decrease mortality. As with real GDP, nominal health expenditures are converted to constant dollar (1992) using the Consumer Price Index (all items).

\section{Methodology and Empirical Results}

3.1. Descriptive Analysis. In this section, we discuss the time series properties of all variables considered in this paper. Figure 1 plots the aggregate mortality rate, unemployment rate, real GDP per capita, and total health expenditure per capita and shows that all but unemployment are upward trending, while the unemployment rate does not exhibit an obvious trend. Nevertheless, all series are tested for nonstationarity using the Phillip-Perron (PP, 1998) and Dickey-Fuller (ADF, 1979) tests; the results of the PP test for these variables in levels are reported in Table 1, panel (a). According to the PP test, all series are nonstationary at the $5 \%$ significance level; however, for the aggregate death rate, the ADF test yields the ADF statistic of -3.3745 with a critical value of -3.1745 suggesting that the series may be stationary. (Table 1 reports Phillip-Perron statistics for unit root test with a trend for all series except for unemployment. Testing for unit root with trend in the case of the unemployment series yields a PP
TABle 1: Phillip-Perron stationarity test.

(a) Stationarity test in levels

\begin{tabular}{lcc}
\hline Variable & PP statistic & $\begin{array}{c}\text { PP critical value } \\
(5 \%)\end{array}$ \\
\hline Death rate & -1.1822 & -3.4904 \\
Unemployment rate & -1.9982 & -2.9737 \\
Real GDP per capita & -2.2823 & -3.4904 \\
Real health expenditure per capita & -1.7556 & -3.4904 \\
Female death rate & -2.4057 & -3.4904 \\
Male death rate & -2.0220 & -3.4904 \\
\hline
\end{tabular}

(b) Stationarity test in first difference

\begin{tabular}{lcc}
\hline Variable & PP statistic & $\begin{array}{c}\text { PP critical value } \\
(5 \%)\end{array}$ \\
\hline Death rate & -7.9970 & -2.9146 \\
Unemployment rate & -5.8568 & -2.9146 \\
Real GDP per capita & -5.4436 & -2.9146 \\
Real health expenditure per capita & -5.3781 & -2.9146 \\
Female death rate & -9.3015 & -2.9146 \\
Male death rate & -5.9515 & -2.9146 \\
\hline
\end{tabular}

statistic of -1.9334 , which does not change the conclusions. The ADF test confirms all other findings; complete results of the ADF test are available upon request.) Table 1, panel (b), reports results of the PP test when testing for non-stationarity in first differences and indicates that all series are stationary in first differences. (In Table 2, we report the PP results for the death rate assuming that the series is nonstationary in levels. The tests were conducted under the assumption of "no trend," and the critical values reflect this assumption.) Hence, we conclude that unemployment rate, real GDP per capita, and real health expenditure per capita are all stationary in first differences; however, the results with respect to the aggregate death rate are uncertain.

Figure 2 plots the death rate by sex. Irrespective of the time period, the female death rate is lower than male death rate. The first panel shows a continuous fall in the female death rate from the 1950 s (=3.5 per 1000 on average) with a minimal leveling off in the early 1970 s at 2.6 per 1000 . The male death rate exhibits a different pattern from female death rate, fluctuating around 5 per 1000 from the mid-1950s until the mid-1970s at which point it begins to fall continuously reaching approximately 2.8 per 1000 in the 2000s. The PP stationarity test results reported in Table 1 suggest that female death rate and male death rate are nonstationary in levels, with both series being stationary in first difference. (In the case of female death rate, that the ADF statistic is 6.0018, much higher than the critical value, which implies that there is some uncertainty whether the series is nonstationary.)

3.2. Error Correction Model: Aggregate Death Rate. Despite the inconclusive unit root test conducted in Section 3.1 with respect to the death rate, we use an error correction model (ECM) of Hendry $[28,29]$ that introduces past disequilibrium 

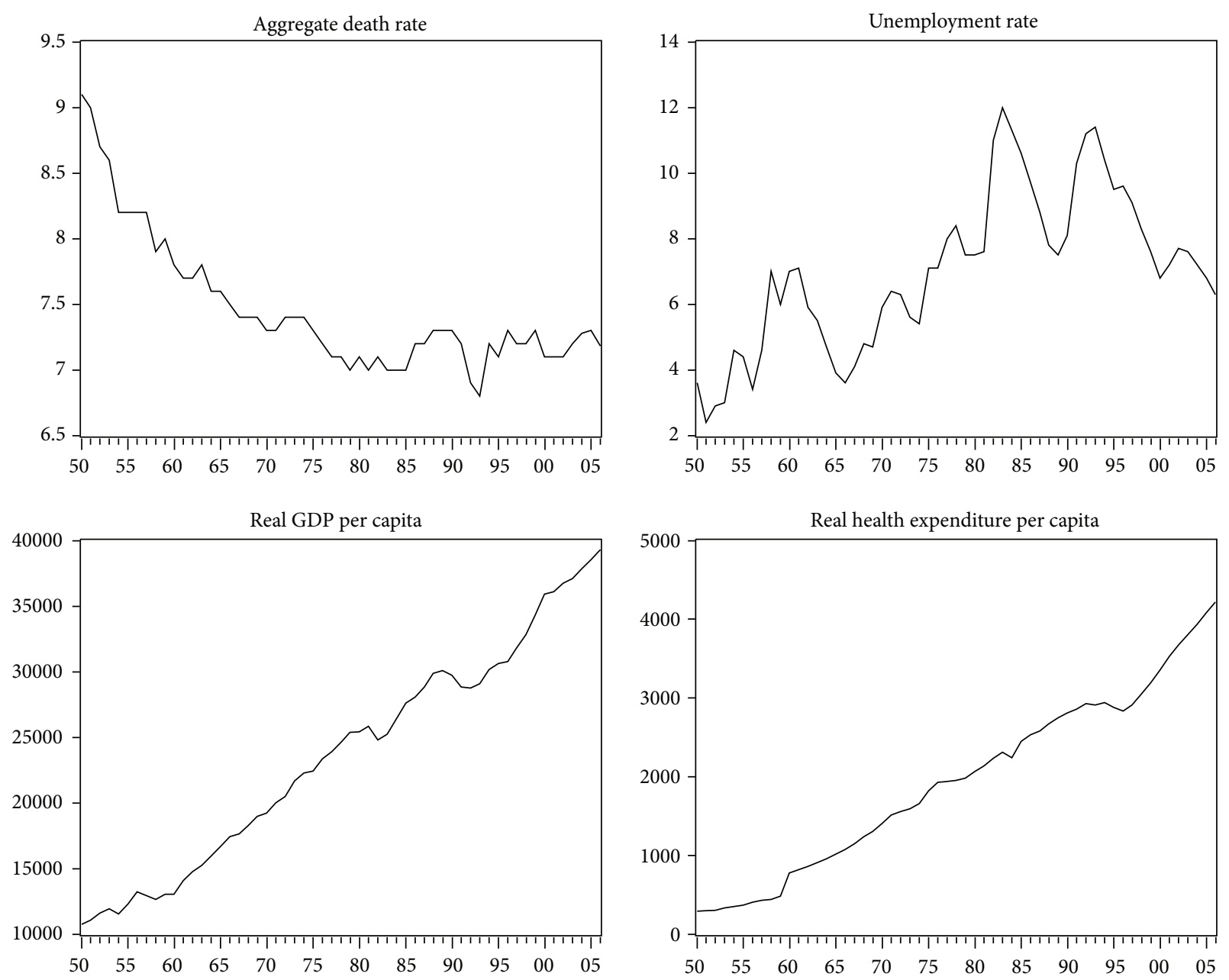

Figure 1: Data series.
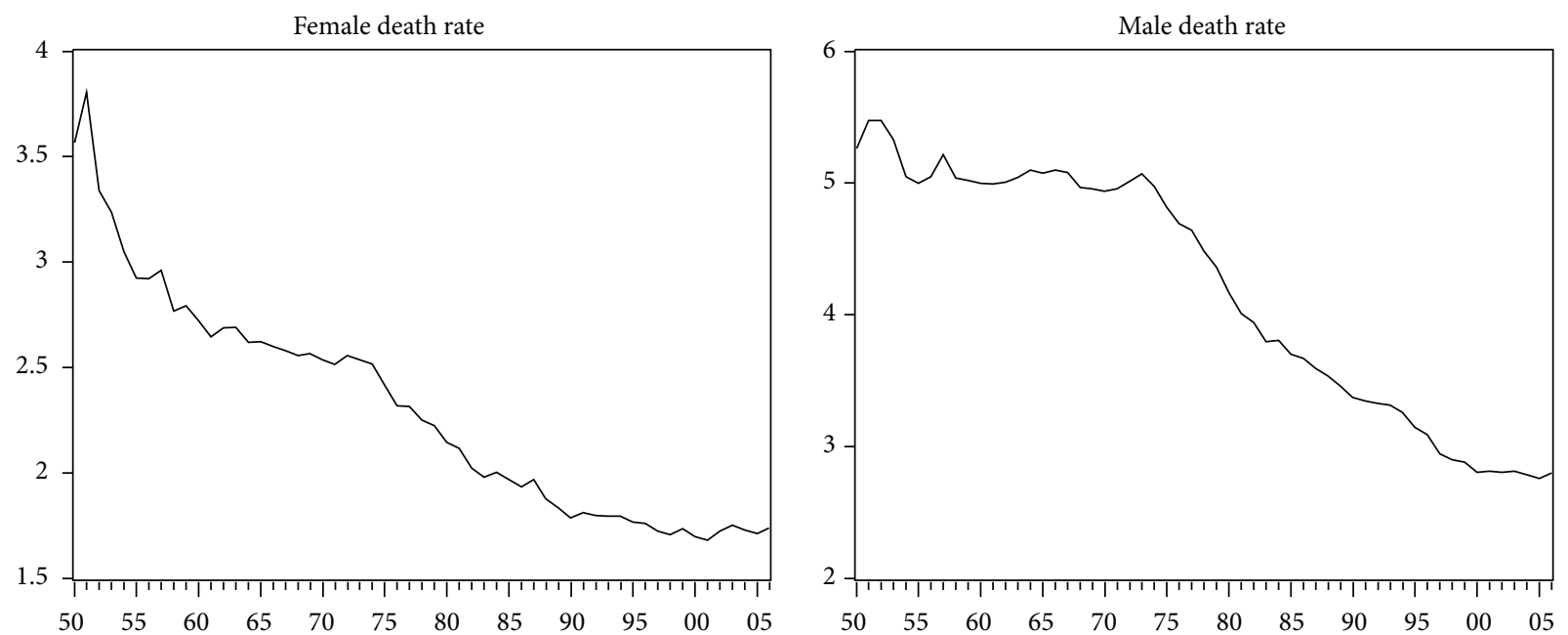

Figure 2: Death rate by sex. 
TABLE 2: Error correction model (2). Total death rate.

\begin{tabular}{|c|c|c|c|c|c|c|}
\hline & \multicolumn{3}{|c|}{ Without dummy variable } & \multicolumn{3}{|c|}{ With dummy variable } \\
\hline & Coefficient & Standard error & $t$-statistic & Coefficient & Standard error & $t$-statistic \\
\hline \multicolumn{7}{|l|}{ Short-run results } \\
\hline Constant & 1.488 & 0.553 & 2.689 & 1.873 & 0.601 & 3.117 \\
\hline$\Delta \mathrm{UR}_{t}$ & -0.045 & 0.026 & -3.281 & -0.085 & 0.025 & -3.323 \\
\hline$\Delta \mathrm{rGDPpc}_{t}$ & $-8.30 E-05$ & $4.75 E-05$ & -1.746 & $-9.89 E-05$ & $4.80 E-05$ & -2.061 \\
\hline$\Delta \mathrm{rHEpc}_{t}$ & $-7.66 E-05$ & $2.81 E-04$ & -0.273 & $-1.74 E-04$ & $2.84 E-04$ & -0.612 \\
\hline $\operatorname{DR}_{t-1}\left(\varphi_{1}=\beta_{1}\right)$ & -0.188 & 0.055 & -3.398 & -0.238 & 0.065 & -3.742 \\
\hline $\mathrm{UR}_{t-1}\left(\beta_{2}\right)$ & -0.010 & 0.012 & -0.8649 & -0.003 & 0.014 & -0.196 \\
\hline $\mathrm{rGDPpc}_{t-1}\left(\beta_{3}\right)$ & $3.29 E-06$ & $2.17 E-06$ & 1.518 & $8.07 E-06$ & $2.16 E-05$ & 0.374 \\
\hline $\mathrm{rHEpc}_{t-1}\left(\beta_{4}\right)$ & $-3.76 E-05$ & 0.001 & -0.226 & $-1.38 E-04$ & $1.77 E-04$ & -0.782 \\
\hline \multirow[t]{4}{*}{ Dummy } & & & & 0.011 & 0.007 & 1.529 \\
\hline & $\mathrm{AIC}=-1.416$ & \multicolumn{2}{|c|}{$R$-square $=0.403$} & $\mathrm{AIC}=-1.4297$ & \multicolumn{2}{|c|}{$R$-square $=0.432$} \\
\hline & $\mathrm{SSR}=0.584$ & \multicolumn{2}{|c|}{$F$-statistic $=4.530$} & $\mathrm{SSR}=0.5557$ & \multicolumn{2}{|c|}{$F$-statistic $=4.369$} \\
\hline & $\mathrm{DW}=2.660$ & \multicolumn{2}{|c|}{ LM F-stat $=3.705$} & $\mathrm{DW}=2.583$ & \multicolumn{2}{|c|}{ LM F-stat $=3.094$} \\
\hline \multicolumn{7}{|l|}{ Long-run results } \\
\hline $\mathrm{UR}_{t-1}\left(\varphi_{2}\right)$ & -0.054 & 0.064 & -0.836 & -0.0105 & 0.053 & -0.199 \\
\hline $\operatorname{rGDPpc}_{t-1}\left(\varphi_{3}\right)$ & $1.75 E-05$ & $1.22 E-04$ & 1.385 & $3.39 E-05$ & $9.13 E-05$ & 0.372 \\
\hline $\mathrm{rHEpc}_{t-1}\left(\varphi_{4}\right)$ & $-2.00 E-04$ & $9.02 E-04$ & -0.188 & $-5.03 E-04$ & $7.60 E-04$ & -0.763 \\
\hline
\end{tabular}

Note: in Tables 2 through 6, columns 1 to 3 show results without dummy, while results in columns 4 to 6 show results including the dummy allowing for a structural break. All standard errors for the long-run estimates are approximated using the Delta Method.

as an explanatory variable in the dynamic behavior of current variables in all our models. (The ECM does not require that all variables be integrated of order 1 ; it can be used whether the variables are $\mathrm{I}(1)$ or $\mathrm{I}(0)$.) Hence, the long-run and shortrun impacts of unemployment, real GDP per capita, and real health expenditure on the death rate are being examined. The initial model follows Laporte [30] and is given by

$$
\begin{aligned}
& \Delta \mathrm{DR}_{t} \\
&=\alpha_{0}+\theta_{1} \Delta \mathrm{UR}_{t}+\theta_{2} \Delta \mathrm{rGDPpc}_{t}+\theta_{2} \Delta \mathrm{rHEpc}_{t} \\
&+\varphi_{1}\left(\mathrm{DR}_{t-1}-\varphi_{2} \mathrm{UR}_{t-1}-\varphi_{3} \mathrm{rGDPpc}_{t-1}-\varphi_{4} \mathrm{rHEpc}_{t-1}\right) \\
&+\mu_{t},
\end{aligned}
$$

where $\mathrm{DR}_{t}$ is the death rate, $\mathrm{UR}_{t}$ is the unemployment rate, $\mathrm{rGDPpc}_{t}$ is real GDP per capita, and $\mathrm{rHEpc}_{t}$ is real health expenditure per capita. In this basic specification, the coefficients on $\Delta \mathrm{UR}_{t}, \Delta \mathrm{rGDPpc}_{t}$, and $\Delta \mathrm{rHEpc}_{t}$ indicate the shortrun impacts of each respective variable on the death rate. The long-run relationship among the four variables is captured by the term in parentheses, which is the disequilibrium in the last period. The ECM model can be rewritten as

$$
\begin{aligned}
\Delta \mathrm{DR}_{t}= & \alpha_{0}+\theta_{1} \Delta \mathrm{UR}_{t}+\theta_{2} \Delta \mathrm{rGDPpc}_{t}+\theta_{2} \Delta \mathrm{rHEpc}_{t} \\
& +\beta_{1} \mathrm{DR}_{t-1}+\beta_{2} \mathrm{UR}_{t-1}+\beta_{3} \mathrm{rGDPpc}_{t-1} \\
& +\beta_{4} \mathrm{rHEpc}_{t-1}+\mu_{t},
\end{aligned}
$$

where $-\beta_{2} / \beta_{1}=\varphi_{2}$ shows the long-run impact of unemployment rate on the death rate. Similarly, $-\beta_{3} / \beta_{1}=\varphi_{3}$ and $-\beta_{4} / \beta_{1}=\varphi_{4}$ show the long-run impact of rGDPpc and rHEpc on the death rate, respectively. Lastly, $\left|\beta_{1}\right|=\left|\varphi_{1}\right|$ is interpreted as the long-run speed of adjustment.

The error correction model in (2) is estimated using standard OLS techniques. Table 2 reports the short-run results, given by the coefficients $\theta_{1}, \theta_{2}$, and $\theta_{3}$ and long-run results given by $\varphi_{2}, \varphi_{3}$, and $\varphi_{4}$. (We use the Delta Method to approximate the standard errors of $\varphi_{2}, \varphi_{3}$, and $\varphi_{4}$ in all our results.) We find only the coefficient on unemployment rate to be statistically significant in the short-run. Moreover, unemployment is negatively related to the death rate, where a $1 \%$ point immediate rise in the unemployment rate leads to a fall in the death rate of 8.5 per 100,000 . The long-run results show that there is no statistically significant long-run relationship between the unemployment rate and total death rate. All other variables are statistically insignificant as well. The aggregate death rate plotted in Figure 1 suggests the possibility of a structural break in the series around 1985; however, a Chow breakpoint test in 1985 yields inconsistent results. (We also consider dates around 1985; however, these yield a lower $F$-statistic and log-likelihood ratio. All Chow break point test results are available upon request.) Nevertheless, we reestimate (2) with a break dummy in 1985; however, the results-reported in Table 2, columns 1 to 3-remain largely unchanged. In both cases, the autocorrelation function (ACF) indicates significant autocorrelations at lags 1 and 7 in the ECM in (2), which suggests that we need to amend the ECM to better fit the data.

We modify the model in (2) by altering the short-run representation with additional lag lengths of the $\Delta$ variables. A number of models are estimated with lag lengths of $t-1$, 
$t-2, t-3$, and $t-4$, and the best model based on the AIC, DW, SSR, and the Breusch-Godfrey serial correlation LM $F$-test is presented here. The modified ECM is given by

$$
\begin{aligned}
\Delta \mathrm{DR}_{t}= & \alpha_{0}+\theta_{1} \Delta \mathrm{UR}_{t}+\theta_{2} \Delta \mathrm{rGDPpc}_{t} \\
& +\theta_{2} \Delta \mathrm{rHEpc}_{t}+\widetilde{\theta}_{1} \Delta \mathrm{DR}_{t-1}+\widetilde{\theta}_{2} \Delta \mathrm{UR}_{t-1} \\
& +\widetilde{\theta}_{3} \Delta \mathrm{rGDPpc}_{t-1}+\widetilde{\theta}_{4} \Delta \mathrm{rHEpc}_{t-1}+\beta_{1} \mathrm{DR}_{t-1} \\
& +\beta_{2} \mathrm{UR}_{t-1}+\beta_{3} \mathrm{rGDPpc}_{t-1}+\beta_{4} \mathrm{rHEpc}_{t-1}+\mu_{t}
\end{aligned}
$$

A Chow break point test in 1985 again gives inconsistent results, and hence we reestimate the model in (3) with a break dummy in 1985. Overall, the model without a dummy variable performs better based on the diagnostic tests. The estimated short-run and long-run results of the regression given in (3) are reported in Table 3 . We find unemployment in the short run to be statistically significant only at time $t$ with the death rate being significant at lag 1 . We find that a $1 \%$ point increase in unemployment rate lowers the death rate by approximately 7.4 per 100,000 , which is equivalent to 2500 deaths avoided in Canada. In addition, a rise in the death rate last period has a small negative impact on the death rate today. None of the long run estimates are statistically significant, and hence there does not exist a long-run relationship between aggregate death rate and unemployment, real GDP per capita, and health expenditure per capita. Nevertheless, at the aggregate level, the results of our ECM analysis support the argument made by Ruhm [1] that recessions are good for your health; we do not find recessions to be detrimental to health as in Brenner [19], Gerdtham and Johannesson [12], and Svensson [13].

We consider alternative specifications of the model as in Section 3.2, and however the specification given in (4) is the best specification of the ECM model for females. (Results for the second best specification are available upon request.) Consequently, we find that during recessions-as indicated by the rise in unemployment rates-female mortality rates fall, and hence recessions are better for female health.

3.3. Findings for Females. We start by estimating the basic representation of ECM in (1) now given by

$$
\begin{aligned}
\Delta \mathrm{FDR}_{t}= & \alpha_{0}+\theta_{1} \Delta \mathrm{UR}_{t}+\theta_{2} \Delta \mathrm{rGDPpc}_{t}+\theta_{2} \Delta \mathrm{rHEpc}_{t} \\
& +\beta_{1} \mathrm{FDR}_{t-1}+\beta_{2} \mathrm{UR}_{t-1}+\beta_{3} \mathrm{rGDPpc}_{t-1} \\
& +\beta_{4} \mathrm{rHEpc}_{t-1}+\mu_{t}
\end{aligned}
$$

where $\mathrm{FDR}_{t}$ is the female death rate. These results are reported in Table 4 . In addition, given the possible structural change observed in Figure 2, we test for a break in the early 1970 s and find the lowest $F$-statistic and log-likelihood ratio in 1971. The results of the ECM with a pulse dummy in 1971 are reported in Table 4 and show slight improvements. (In addition, the Cusum of squares test results show the model with a dummy to be stable, while the one without a dummy indicates some instability. Results are available upon request.) In the short run, unemployment and real GDP per capita are both statistically significant and negatively related to the female death rate. Specifically, a rise in unemployment by $1 \%$ point in a given year causes a fall in the death rate of 6.5 per 100,000 in that same year. Moreover, the long-run results also indicate a negative significant relationship between the female death rate and unemployment. Specifically, a rise in the unemployment rate by $1 \%$ point causes a fall in the female death rate by 0.0851 per 1000 in the long run, in other words, approximately 8.5 per 100,000 deaths over time. The coefficient on $\mathrm{DR}_{t-1}$ (equal to -0.2692) indicates the speed of adjustment. Hence, $26.9 \%$ of the long-run adjustment in the female death rate occurs in the subsequent year, which is a fall of 2.29 per 100,000 . This is followed by a fall of 1.67 per 100,000 in the following year and so on. This implies that approximately $99 \%$ of the fall in the death rate occurs within 10 years following the change in unemployment. This, given the size of the female population, translates to a fall of approximately 1400 female deaths over that time frame in addition to the 1100 females deaths avoided within the first year.

We also find real GDP per capita to be negatively related to the death rate in the long run; all these results are statistically significant at conventional levels. In contrast, we do not find real health expenditure per person to be statistically significant.

3.4. Findings for Males. We start by estimating the basic ECM in (4) using the male death rate, and report our results in Table 5. However, a Chow breakpoint test in 1974 indicates that we fail to reject the hypothesis of no structural break, and hence we reestimate the ECM in (4) with a dummy variable and report those findings in Table 5 as well. Using the latter model, we find the coefficient estimate for unemployment in the short run to be statistically significant, and furthermore, unemployment rate, real GDP per capita, and real health Expenditure per capital are all significant in the long run. However, according to the DW statistic, there remains some serial correlations in the errors, and hence we estimate a modified ECM for males.

The best specification for male death rate (MDR) is given by

$$
\begin{aligned}
\Delta \mathrm{MDR}_{t}= & \alpha_{0}+\widetilde{\theta}_{1} \Delta \mathrm{MDR}_{t-1}+\widetilde{\theta}_{2} \Delta \mathrm{UR}_{t-2} \\
& +\widetilde{\theta}_{3} \Delta \mathrm{rGDPpc}_{t-1}+\widetilde{\theta}_{4} \Delta \mathrm{rHEpc}_{t-1}+\widetilde{\theta}_{5} \Delta \mathrm{MDR}_{t-2} \\
& +\widetilde{\theta}_{6} \Delta \mathrm{UR}_{t-2}+\widetilde{\theta}_{7} \Delta \mathrm{rGDPpc}_{t-2}+\widetilde{\theta}_{8} \Delta \mathrm{rHEpc}_{t-2} \\
& +\widetilde{\theta}_{9} \Delta \mathrm{MDR}_{t-3}+\widetilde{\theta}_{10} \Delta \mathrm{UR}_{t-3}+\widetilde{\theta}_{11} \Delta \mathrm{rGDPpc}_{t-3} \\
& +\widetilde{\theta}_{12} \Delta \mathrm{rHEpc}_{t-3}+\widetilde{\theta}_{13} \Delta \mathrm{MDR}_{t-4}+\widetilde{\theta}_{14} \Delta \mathrm{UR}_{t-4} \\
& +\widetilde{\theta}_{15} \Delta \mathrm{rGDPpc}_{t-4}+\widetilde{\theta}_{16} \Delta \mathrm{rHEpc}_{t-4} \\
& +\beta_{1} \mathrm{MDR}_{t-1}+\beta_{2} \mathrm{UR}_{t-1} \\
& +\beta_{3} \mathrm{rGDPpc}_{t-1}+\beta_{4} \mathrm{rHEpc}_{t-1}+\mu_{t} .
\end{aligned}
$$

The results of the model in (5) with and without a trend dummy in 1974 are given in Table 6. (There are not enough data points available to run the Chow breakpoint test. 
TABle 3: Modified error correction model (3). Total death rate.

\begin{tabular}{|c|c|c|c|c|c|c|}
\hline & \multicolumn{3}{|c|}{ Without dummy variable } & \multicolumn{3}{|c|}{ With dummy variable } \\
\hline & Coefficient & Standard error & $t$-statistic & Coefficient & Standard error & $t$-statistic \\
\hline \multicolumn{7}{|l|}{ Short-run results } \\
\hline Constant & 1.574 & 0.722 & 2.181 & 2.378 & 0.831 & 2.860 \\
\hline$\Delta \mathrm{UR}_{t}$ & -0.074 & 0.033 & -2.204 & -0.072 & 0.033 & -2.215 \\
\hline$\Delta \mathrm{rGDPpc}_{t}$ & $-7.51 E-05$ & $5.81 E-05$ & -1.292 & $-9.50 E-05$ & $5.76 E-05$ & -1.649 \\
\hline$\Delta \mathrm{rHEpc}_{t}$ & $-6.70 E-05$ & $3.28 E-04$ & -0.204 & $-1.98 E-04$ & $3.28 E-04$ & -0.606 \\
\hline$\Delta \mathrm{UR}_{t-1}$ & -0.001 & 0.034 & -0.028 & -0.012 & 0.034 & -0.356 \\
\hline$\Delta \mathrm{rGDPpc}_{t-1}$ & $2.11 E-05$ & $6.90 E-05$ & 0.305 & $4.99 E-06$ & $6.77 E-05$ & 0.074 \\
\hline$\Delta \mathrm{rHEpc}_{t-1}$ & $-5.74 E-05$ & $3.31 E-04$ & -0.174 & $-6.19 E-06$ & $3.23 E-04$ & -0.019 \\
\hline$\Delta \mathrm{UR}_{t-2}$ & $-6.83 E-04$ & 0.030 & -0.023 & -0.015 & 0.030 & -0.495 \\
\hline$\Delta \mathrm{rGDPpc}_{t-2}$ & $1.06 E-05$ & $6.17 E-05$ & 0.172 & $-6.16 E-06$ & $6.07 E-05$ & -0.102 \\
\hline$\Delta \mathrm{rHEpc}_{t-2}$ & $4.31 E-05$ & $3.17 E-04$ & 0.136 & $1.27 E-04$ & $3.12 E-04$ & 0.408 \\
\hline $\mathrm{DR}_{t-1}\left(\varphi_{1}=\beta_{1}\right)$ & -0.193 & 0.078 & -2.464 & -0.302 & 0.097 & -3.106 \\
\hline $\mathrm{UR}_{t-1}\left(\beta_{2}\right)$ & -0.007 & 0.015 & -0.493 & -0.006 & 0.016 & 0.359 \\
\hline $\operatorname{rGDPpc}_{t-1}\left(\beta_{3}\right)$ & $-5.02 E-06$ & $3.32 E-05$ & -0.151 & $6.36 E-06$ & $3.29 E-05$ & 0.193 \\
\hline $\mathrm{rHEpc}_{t-1}\left(\beta_{4}\right)$ & $1.89 E-05$ & 0.001 & 0.074 & $-1.75 E-04$ & 0.001 & -0.646 \\
\hline \multirow[t]{4}{*}{ Dummy } & & & & 0.016 & 0.009 & 1.803 \\
\hline & $\mathrm{AIC}=-1.391$ & \multicolumn{2}{|c|}{$R$-square $=0.482$} & $\mathrm{AIC}=-3.055$ & \multicolumn{2}{|c|}{$R$-square $=0.770$} \\
\hline & $\mathrm{SSR}=0.505$ & \multicolumn{2}{|c|}{$F$-statistic $=3.549$} & $\mathrm{SSR}=0.059$ & \multicolumn{2}{|c|}{$F$-statistic $=4.634$} \\
\hline & $\mathrm{DW}=2.607$ & \multicolumn{2}{|c|}{ LM $F$-stat $=2.852$} & $\mathrm{DW}=2.546$ & \multicolumn{2}{|c|}{ LM $F$-stat $=2.829$} \\
\hline \multicolumn{7}{|l|}{ Long-run results } \\
\hline $\mathrm{UR}_{t-1}\left(\varphi_{2}\right)$ & -0.038 & 0.078 & -0.487 & -0.019 & 0.054 & -0.354 \\
\hline $\operatorname{rGDPpc}_{t-1}\left(\varphi_{3}\right)$ & $-2.60 E-05$ & $1.72 E-04$ & -0.151 & $2.11 E-05$ & $1.09 E-04$ & 0.193 \\
\hline $\mathrm{rHEpc}_{t-1}\left(\varphi_{4}\right)$ & $9.78 E-05$ & $1.35 E-04$ & 0.073 & $-5.80 E-04$ & $1.01 E-03$ & -0.573 \\
\hline
\end{tabular}

TABLE 4: Error correction model (4). Female death rate.

\begin{tabular}{|c|c|c|c|c|c|c|}
\hline & \multicolumn{3}{|c|}{ Without dummy variable } & \multicolumn{3}{|c|}{ With dummy variable } \\
\hline & Coefficient & Standard error & $t$-statistic & Coefficient & Standard error & $t$-statistic \\
\hline \multicolumn{7}{|l|}{ Short-run results } \\
\hline Constant & 0.996 & 0.322 & 3.096 & 1.226 & 0.373 & 3.288 \\
\hline$\Delta \mathrm{UR}_{t}$ & -0.058 & 0.017 & -3.521 & -0.065 & 0.017 & -3.737 \\
\hline$\Delta \mathrm{rGDPpc}_{t}$ & $-5.46 E-05$ & $3.07 E-05$ & -2.107 & $-7.22 E-05$ & $3.12 E-05$ & -2.318 \\
\hline$\Delta \mathrm{rHEpc}_{t}$ & $6.30 E-05$ & $2.00 E-04$ & 0.338 & $1.07 E-04$ & $1.89 E-04$ & 0.566 \\
\hline $\mathrm{DR}_{t-1}\left(\varphi_{1}=\beta_{1}\right)$ & -0.236 & 0.074 & -3.212 & -0.269 & 0.078 & -3.445 \\
\hline $\mathrm{UR}_{t-1}\left(\beta_{2}\right)$ & -0.016 & 0.008 & -1.859 & -0.023 & 0.010 & -2.221 \\
\hline $\mathrm{rGDPpc}_{t-1}\left(\beta_{3}\right)$ & $-2.34 E-05$ & $1.46 E-05$ & -1.602 & $-3.31 E-05$ & $1.66 E-05$ & -1.992 \\
\hline $\mathrm{rHEpc}_{t-1}\left(\beta_{4}\right)$ & $1.08 E-05$ & $1.10 E-04$ & 0.985 & $1.53 E-04$ & $1.15 E-04$ & 1.330 \\
\hline \multirow[t]{4}{*}{ Dummy } & & & & 0.059 & 0.049 & 1.206 \\
\hline & $\mathrm{AIC}=-2.248$ & \multicolumn{2}{|c|}{$R$-squared $=0.372$} & $\mathrm{AIC}=-2.243$ & \multicolumn{2}{|c|}{$R$-squared $=0.391$} \\
\hline & $\mathrm{SSR}=0.254$ & \multicolumn{2}{|c|}{$F$-statistic $=3.978$} & $\mathrm{SSR}=0.247$ & \multicolumn{2}{|c|}{$F$-statistic $=3.696$} \\
\hline & $\mathrm{DW}=1.979$ & \multicolumn{2}{|c|}{ LM F-stat $=1.308$} & $\mathrm{DW}=1.961$ & \multicolumn{2}{|c|}{ LM F-stat $=1.263$} \\
\hline \multicolumn{7}{|l|}{ Long-run results } \\
\hline $\mathrm{UR}_{t-1}\left(\varphi_{2}\right)$ & -0.067 & 0.028 & -2.382 & -0.085 & 0.028 & -3.047 \\
\hline $\operatorname{rGDPpc}_{t-1}\left(\varphi_{3}\right)$ & $-9.92 E-05$ & $6.18 E-05$ & -1.604 & $-1.23 E-05$ & $5.86 E-05$ & -2.099 \\
\hline $\mathrm{rHEpc}_{t-1}\left(\varphi_{4}\right)$ & 0.001 & $1.05 E-03$ & 0.947 & $5.68 E-04$ & $4.38 E-04$ & 1.297 \\
\hline
\end{tabular}


TABLE 5: Error correction model (2). Male death rate.

\begin{tabular}{|c|c|c|c|c|c|c|}
\hline & \multicolumn{3}{|c|}{ Without dummy variable } & \multicolumn{3}{|c|}{ With dummy variable } \\
\hline & Coefficient & Standard error & $t$-statistic & Coefficient & Standard error & $t$-statistic \\
\hline \multicolumn{7}{|l|}{ Short-run results } \\
\hline Constant & 0.841 & 0.290 & 2.899 & 2.580 & 0.587 & 4.399 \\
\hline$\Delta \mathrm{UR}_{t}$ & -0.039 & 0.018 & -2.193 & -0.041 & 0.016 & -2.586 \\
\hline$\Delta \mathrm{rGDPpc}_{t}$ & $-3.03 E-05$ & $3.27 E-05$ & -0.926 & $-1.90 E-05$ & $2.99 E-05$ & -0.637 \\
\hline$\Delta \mathrm{rHEpc}_{t}$ & $1.51 E-04$ & $1.92 E-04$ & 0.785 & $1.00 E-04$ & $1.75 E-04$ & 0.635 \\
\hline $\mathrm{DR}_{t-1}\left(\varphi_{1}=\beta_{1}\right)$ & -0.067 & 0.040 & -1.674 & -0.362 & 0.096 & -3.770 \\
\hline $\mathrm{UR}_{t-1}\left(\beta_{2}\right)$ & -0.018 & 0.007 & -2.618 & -0.042 & 0.010 & -4.396 \\
\hline $\mathrm{rGDPpc}_{t-1}\left(\beta_{3}\right)$ & $-4.33 E-05$ & $1.48 E-05$ & -2.918 & $-5.79 E-05$ & $1.42 E-05$ & -4.088 \\
\hline $\mathrm{rHEpc}_{t-1}\left(\beta_{4}\right)$ & $2.85 E-04$ & $1.15 E-04$ & 2.485 & $4.00 E-04$ & $1.09 E-04$ & 3.684 \\
\hline \multirow[t]{4}{*}{ Dummy } & & & & -0.022 & 0.007 & -3.319 \\
\hline & $\mathrm{AIC}=-2.172$ & \multicolumn{2}{|c|}{$R$-square $=0.309$} & $\mathrm{AIC}=-2.350$ & \multicolumn{2}{|c|}{$R$-square $=0.442$} \\
\hline & $\mathrm{SSR}=0.274$ & \multicolumn{2}{|c|}{$F$-statistic $=2.996$} & $\mathrm{SSR}=0.221$ & \multicolumn{2}{|c|}{$F$-statistic $=4.557$} \\
\hline & $\mathrm{DW}=1.542$ & \multicolumn{2}{|c|}{ LM F-stat $=1.321$} & $\mathrm{DW}=1.416$ & \multicolumn{2}{|c|}{ LM F-stat $=2.669$} \\
\hline \multicolumn{7}{|l|}{ Long-run results } \\
\hline $\mathrm{UR}_{t-1}\left(\varphi_{2}\right)$ & -0.275 & 0.173 & -1.593 & -0.115 & 0.021 & -5.577 \\
\hline $\operatorname{rGDPpc}_{t-1}\left(\varphi_{3}\right)$ & $-6.00 E-04$ & $3.89 E-04$ & -1.544 & -1.60 & $4.78 E-05$ & -3.346 \\
\hline $\mathrm{rHEpc}_{t-1}\left(\varphi_{4}\right)$ & 0.004 & 0.003 & 1.313 & 0.001 & $3.26 E-04$ & 3.069 \\
\hline
\end{tabular}

Nevertheless, we use the Cusum of squares stability test on (5) with and without a dummy to determine the better fitting model and find no instability in the modified ECM with a dummy for males.)

The results indicate that a change in unemployment rate in a given year does not affect the death rate in that year. This is in contrast to the findings for females. However, unemployment rate is positively and statistically significant at lags 2 and 3, with the coefficient on unemployment being higher at lag 2 than at lag 3. Similar findings hold for real GDP per capita. Thus, as compared to female death rate, the impact of unemployment and real GDP per capita takes time to come into effect in the case of males.

With respect to the male death rate, a $1 \%$ increase in unemployment leads to an approximate fall of 9 per 100,000 in the male death rate over time. Specifically, approximately $50 \%(=4.5$ per 100,000$)$ of this fall occurs the next year, with a fall of 2.25 per 100,000 the subsequent year. With the male's speed of adjustment to long-run equilibrium being almost twice as fast for males versus females, it takes approximately six years for $99 \%$ of the adjustment in the male death rate to occur. Hence, given the size of the male population, this translates to a fall of approximately 1500 deaths over six years.

We also find both real GDP per capita and real health expenditure per capita to be significant. Specifically, we find that a rise in GDP per person has a positive effect on death rates, unlike the negative effect on females, although quantitatively the impact is quite small. Increases in health expenditure per person have a negative effect on male death rates, while for females, this was insignificant. Overall, when it comes to unemployment, as a measure of economic activity, the results of our analysis indicate that recessions are good for the health (as measured by the death rate) of both females and males in Canada.

\section{Conclusion}

Current research indicates that in a number of developed countries, recessions are associated with lower mortality rates, suggesting that recessions are good for one's health. This finding follows from prominent works conducted by Ruhm [1-3], Gerdtham and Ruhm [10], Tapia Granados [6], and Arizumi and Schirle [14] among others and is confirmed in this paper using an error correction model with Canadian data from 1950 to 2006. The use of a time series error correction model allows us to determine the short-run and long-run impacts of unemployment on death rate. Our results indicate that a $1 \%$ point increase in unemployment rate lowers the aggregate death rate by approximately 7.4 per 100,000 , an equivalent of 2500 deaths avoided in Canada. For females, a rise in the unemployment rate by $1 \%$ point has an immediate impact of a 6.5 per 100,000 fall in the death rate and a fall in the female death rate by approximately 8.5 per 100,000 over time, with $26.9 \%$ of the long-run adjustment in unemployment occurring next year. This translates to approximately 2500 female deaths avoided over eleven years. The results for males indicate a fall of 1500 deaths in the six years following a rise in unemployment by $1 \%$ point in a given year. Consequently, we find that recessions are good for one's health in Canada.

Unlike the common believe that recessions are bad for one's health, we find that it is during periods of tight labor markets that mortality rates increase for both men and women. While this is counter to common beliefs, it is consistent with the majority of the findings in the literature. Hence, while the media in Canada may urge "the federal government (needs) to focus more attention on health care" during times of recession [26], our results suggest that policy makers cannot ignore expansionary periods when addressing the population's heath. 
TABLE 6: Modified error correction model (5). Male death rate.

\begin{tabular}{|c|c|c|c|c|c|c|}
\hline & \multicolumn{3}{|c|}{ Without dummy variable } & \multicolumn{3}{|c|}{ With dummy variable } \\
\hline & Coefficient & Standard error & $t$-statistic & Coefficient & Standard error & $t$-statistic \\
\hline \multicolumn{7}{|l|}{ Short-run results } \\
\hline Constant & 1.623 & 0.383 & 4.244 & 3.543 & 0.670 & 5.064 \\
\hline$\Delta \mathrm{MDR}_{t-1}$ & -0.021 & 0.142 & -0.147 & 0.097 & 0.130 & 0.743 \\
\hline$\Delta \mathrm{UR}_{t-1}$ & -0.007 & 0.016 & -0.444 & 0.015 & 0.016 & 0.922 \\
\hline$\Delta \mathrm{rGDPpc}_{t-1}$ & $7.03 E-05$ & $3.49 E-05$ & 2.014 & $1.11 E-04$ & $3.95 E-05$ & 2.808 \\
\hline$\Delta \mathrm{rHEpc}_{t-1}$ & $4.10 E-05$ & $2.00 E-04$ & 0.263 & $-1.05 E-04$ & $1.28 E-04$ & -0.819 \\
\hline$\Delta \mathrm{MDR}_{t-2}$ & 0.138 & 0.126 & 1.097 & 0.251 & 0.117 & 2.151 \\
\hline$\Delta \mathrm{UR}_{t-2}$ & 0.033 & 0.017 & 1.905 & 0.046 & 0.016 & 2.916 \\
\hline$\Delta \mathrm{rGDPpc}_{t-2}$ & $4.78 E-05$ & $3.47 E-05$ & 1.376 & $1.01 E-04$ & $5.01 E-05$ & 2.014 \\
\hline$\Delta \mathrm{rHEpc}_{t-2}$ & $-1.09 E-04$ & $1.91 E-04$ & -0.570 & $-2.22 E-04$ & $2.36 E-04$ & -0.942 \\
\hline$\Delta \mathrm{MDR}_{t-3}$ & -0.266 & $1.30 \mathrm{E}-01$ & -2.039 & -0.148 & 0.121 & -1.223 \\
\hline$\Delta \mathrm{UR}_{t-3}$ & 0.022 & 0.0184 & 1.212 & 0.037 & 0.017 & 2.179 \\
\hline$\Delta \mathrm{rGDPpc}_{t-3}$ & $6.56 E-05$ & $3.63 E-05$ & 1.807 & $1.19 E-04$ & $6.46 E-05$ & 2.305 \\
\hline$\Delta \mathrm{rHEpc}_{t-3}$ & $-2.00 E-04$ & $1.91 E-04$ & -1.046 & $-2.75 E-04$ & $1.89 E-04$ & -1.459 \\
\hline$\Delta \mathrm{MDR}_{t-4}$ & -0.162 & 0.1735 & -0.934 & -0.067 & 0.156 & -0.432 \\
\hline$\Delta \mathrm{UR}_{t-4}$ & -0.011 & 0.0150 & -0.720 & 0.006 & 0.014 & 0.413 \\
\hline$\Delta \mathrm{rGDPpc}_{t-4}$ & $6.25 E-06$ & $4.48 E-06$ & 1.396 & $1.63 E-04$ & $7.88 E-05$ & 2.067 \\
\hline$\Delta \mathrm{rHEpc}_{t-4}$ & $1.00 E-04$ & $2.00 E-04$ & 0.604 & $5.50 E-05$ & $1.44 E-04$ & 0.382 \\
\hline $\mathrm{DR}_{t-1}\left(\varphi_{1}=\beta_{1}\right)$ & -0.143 & 0.036 & -3.944 & -0.486 & 0.114 & -4.257 \\
\hline $\mathrm{UR}_{t-1}\left(\beta_{2}\right)$ & -0.020 & $8.72 E-03$ & -2.342 & -0.044 & 0.011 & -4.094 \\
\hline $\operatorname{rGDPpc}_{t-1}\left(\beta_{3}\right)$ & $-8.96 E-05$ & $2.86 E-05$ & -3.134 & $-9.5 E-05$ & $2.44 E-05$ & -3.893 \\
\hline $\mathrm{rHEpc}_{t-1}\left(\beta_{4}\right)$ & $5.53 E-04$ & $2.09 E-04$ & 2.640 & $6.68 E-04$ & $1.97 E-04$ & 3.388 \\
\hline \multirow[t]{4}{*}{ Dummy } & & & & -0.024 & 0.008 & -3.129 \\
\hline & $\mathrm{AIC}=-2.804$ & \multicolumn{2}{|c|}{$R$-square $=0.693$} & $\mathrm{AIC}=-3.055$ & \multicolumn{2}{|c|}{$R$-square $=0.770$} \\
\hline & $\mathrm{SSR}=0.079$ & \multicolumn{2}{|c|}{$F$-statistic $=3.384$} & $\mathrm{SSR}=0.059$ & \multicolumn{2}{|c|}{$F$-statistic $=4.634$} \\
\hline & $\mathrm{DW}=2.114$ & \multicolumn{2}{|c|}{ LM F-stat $=0.167$} & $\mathrm{DW}=2.227$ & \multicolumn{2}{|c|}{ LM $F$-stat $=1.450$} \\
\hline \multicolumn{7}{|l|}{ Long-run results } \\
\hline $\mathrm{UR}_{t-1}\left(\varphi_{2}\right)$ & -0.1428 & 0.0622 & 2.2969 & -0.0909 & 0.0160 & 5.6657 \\
\hline $\operatorname{rGDPpc}_{t-1}\left(\varphi_{3}\right)$ & $6.27 E-04$ & $2.04 E-04$ & 3.0661 & $2.03 E-04$ & $6.27 E-05$ & 3.2308 \\
\hline $\mathrm{rHEpc}_{t-1}\left(\varphi_{4}\right)$ & $-3.87 E-03$ & $1.55 E-03$ & -2.4998 & $-1.30 E-03$ & $4.40 E-04$ & -2.9457 \\
\hline
\end{tabular}

In this paper, we focused on determining whether a shortrun and a long-run relationships between mortality rates and recessions exist, and however we did not go further to address why recessions lead to lower mortality rates in Canada, especially when considering the different impacts across gender, and why do they have lasting long-run effects. (Unlike our paper, Gerdtham and Johannesson [12] find that recessions adversely affect the health of men but have no effect on the health of women. They argue that this may be due to men being more sensitive to the changes in the labor market, especially when they are the breadwinner.) Miller et al. [32] consider the mechanisms that are most likely to yield a procyclical relationship between economic activity and health in US data. The authors specifically consider that the role of individual health changes due to changes in one's work versus the role of external business cycle sources. They find external sources to be more significant in the beginning to understand the reasons behind the positive effects on health from declines in economic activity. Browning and Heinesen [33] find that workers who became unemployed specifically as a result of plant closures had higher mortality rates. A better understanding of the reasons for the positive long-run relationship in Canada is left for future research.

\section{Appendix}

\section{Data Sources}

Death Rate. We obtain death rate per 1000 for males and females separately, as well as in total. For 1950-1975, the source is Historical Statistics Canada series B18 (total), B16 (males), and B17 (female). 
Unemployment Rate. For 1950-1975, the source is Historical Statistics Canada series D233 (total), and for 1976-2006, the source is CANSIM II, table 282-0086.

Gross National Product (nominal). For 1950-1975, the source is Historical Statistics Canada series F13. For 1976-2006, the source is Statistics Canada, table 379-0024.

Consumer Price Index. We obtain CPI in 1992 dollars with a 2001 basket. For 1950-2006, the source is CANSIM II, table 326-0002.

Population. For 1950-1975, the source is Historical Statistics Canada series A1. For 1976-2006, the source is CANSIM II, table 051-0001.

Health Expenditure. For 1950-1975, the source is Historical Statistics Canada (vital statistics) series B513. For 1976-2006, the source is Canadian Institute of Health Information, table A.3.3.1.

\section{References}

[1] C. J. Ruhm, "Are recessions good for your health?” Quarterly Journal of Economics, vol. 115, no. 2, pp. 617-650, 2000.

[2] C. J. Ruhm, "Good times make you sick," Journal of Health Economics, vol. 22, no. 4, pp. 637-658, 2003.

[3] C. J. Ruhm, "Commentary: mortality increases during economic upturns," International Journal of Epidemiology, vol. 34, no. 6, pp. 1206-1211, 2005.

[4] C. J. Ruhm, Microeconomic Conditions, Health and government Policy, Mimeo, University of North Carolina at Greensboro, Greensboro, NC, USA, 2006.

[5] E. Neumayer, "Recessions lower (some) mortality rates: evidence from Germany," Social Science and Medicine, vol. 58, no. 6, pp. 1037-1047, 2004.

[6] J. A. Tapia Granados, "Recessions and mortality in Spain, 19801997," European Journal of Population, vol. 21, no. 4, pp. 393-422, 2005.

[7] J. A. Tapia Granados, "Macroeconomic fluctuations and mortality in postwar Japan," Demography, vol. 45, no. 2, pp. 323-343, 2008.

[8] Y.-H. Khang, J. W. Lynch, and G. A. Kaplan, "Impact of economic crisis on cause-specific mortality in South Korea," International Journal of Epidemiology, vol. 34, no. 6, pp. 1291-1301, 2005.

[9] F. Abdala, R. N. Geldsteain, and S. M. Mychaszula, "Economic restructuring and mortality changes in Argentina-is there any connection?" in Moratlity Crisis in Transitional Economies, G. A. Cornia and R. Paniccia, Eds., pp. 328-350, Oxford University Press, New York, NY, USA, 2000.

[10] U.-G. Gerdtham and C. J. Ruhm, "Deaths rise in good economic times: evidence from the OECD," Economics and Human Biology, vol. 4, no. 3, pp. 298-316, 2006.

[11] I. D. McAvinchey, "A comparison of unemployment, income and mortality interaction for five European countries," Applied Economics, vol. 20, no. 4, pp. 453-471, 1988.

[12] U.-G. Gerdtham and M. Johannesson, "Business cycles and mortality: results from swedish microdata," Social Science and Medicine, vol. 60, no. 1, pp. 205-218, 2005.
[13] M. Svensson, "Do not go breaking your heart: do economic upturns really increase heart attack mortality?" Social Science and Medicine, vol. 65, no. 4, pp. 833-841, 2007.

[14] H. Arizumi and T. Schirle, "Are recessions really good for your health? Evidence from Canada," Working Paper number, 2011.

[15] M. H. Brenner, Mental Illness and the Economy, Harvard University Press, Cambridge, Mass, USA, 1973.

[16] W. F. Ogburn and D. S. Thomas, "The influence of the business cycle on certain social conditions," Journal of the American Statistical Association, vol. 18, pp. 324-340, 1922.

[17] D.S. Thomas, Social Aspects of the Business Cycle, Knopf, New York, NY, USA, 1927.

[18] M. H. Brenner, "Trends in alcohol consumption and associated illnesses. Some effects of economic changes," American Journal of Public Health, vol. 65, no. 12, pp. 1279-1292, 1975.

[19] M. H. Brenner, "Mortality and the national economy: a review, and the experience of England and Wales, 1936-76," The Lancet, vol. 2, no. 8142, pp. 568-573, 1979.

[20] H. S. Gravelle, G. Hutchinson, and J. Stern, "Mortality and unemployment: a critique of brenner's time-series analysis," The Lancet, vol. 2, no. 8248, pp. 675-679, 1981.

[21] S. V. Kasl, "Mortality and the business cycle: some questions about research strategies when utilizing macro-social and ecological data," American Journal of Public Health, vol. 69, no. 8, pp. 784-788, 1979.

[22] J. Stern, “The relationship between unemployment, morbidity and mortality in Britain," Population Studies, vol. 37, no. 1, pp. 61-74, 1983.

[23] A. Wagstaff, "Time series analysis of the relationship between unemployment and mortality: a survey of econometric critiques and replications of Brenner's studies," Social Science and Medicine, vol. 21, no. 9, pp. 985-996, 1985.

[24] K. A. Moser, A. J. Fox, and D. R. Jones, "Unemployment and mortality in the OPCS Longitudinal Study," The Lancet, vol. 2, no. 8415, pp. 1324-1329, 1984.

[25] R. Smith, "The recession is bad for your health, experts warn," March 2009, http://www.telegraph.co.uk/health/healthnews/ 4967199/The-recession-is-bad-for-your-health-experts-warn .html.

[26] A. Raj, "Recession is bad for your health," Sarnia Observer, August 2009.

[27] S. Reinberg, "Recession drove down doctor visits, study says," January 2013, http://health.usnews.com/health-news/news/ articles/2013/01/07/recession-drove-down-doctor-visits-studysays.

[28] D. F. Hendry, "Econometric modeling with cointegrated variables: an overview," Oxford Bulletin of Economics and Statistics, vol. 48, pp. 201-212, 1986.

[29] D. B. Hendry, "An econometric model of United Kingdom building societies," Oxford Bulletin of Economics and Statistics, vol. 46, no. 3, pp. 185-210, 1984.

[30] A. Laporte, "Do economic cycles have a permanent effect on population health? Revisiting the Brenner hypothesis," Health Economics, vol. 13, no. 8, pp. 767-779, 2004.

[31] K. Norrie, D. Owram, and J. C. H. Emery, A History of the Canadian Economy, Nelson Education, Scarborough, UK, 4th edition, 2008.

[32] D. L. Miller, M. E. Page, A. H. Stevens, and M. Filipski, "Why are recessions good for your health?" American Economic Review, vol. 99, no. 2, pp. 122-127, 2009. 
[33] M. Browning and E. Heinesen, "Effect of job loss due to plant closure on mortality and hospitalisation," Journal of Health Economics, vol. 31, no. 4, pp. 599-616, 2012. 

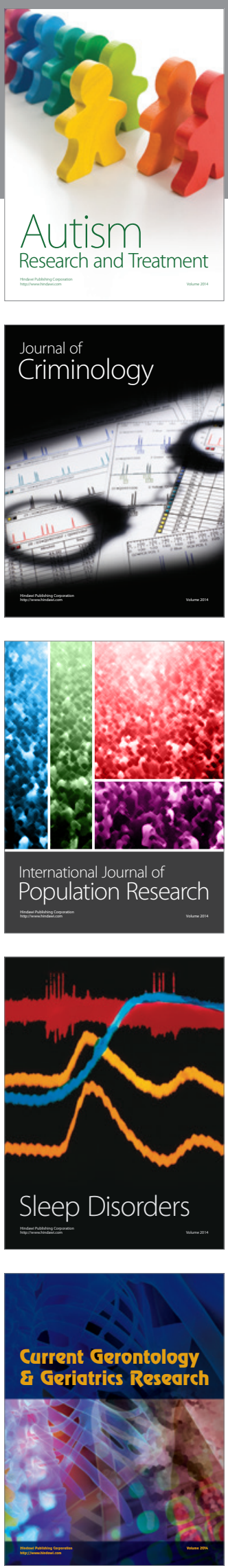
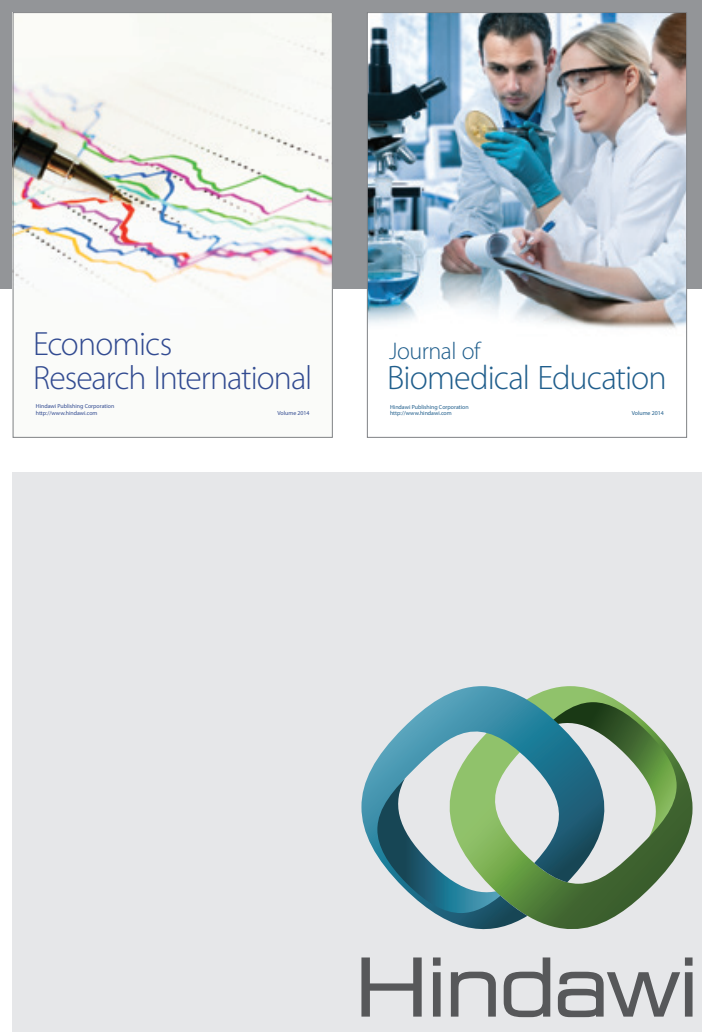

Submit your manuscripts at

http://www.hindawi.com
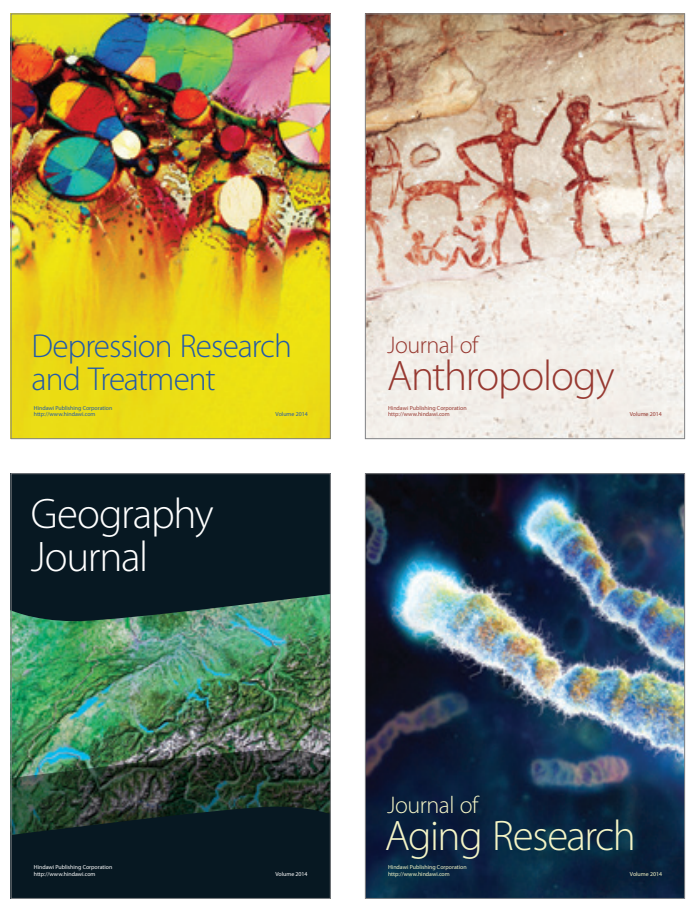
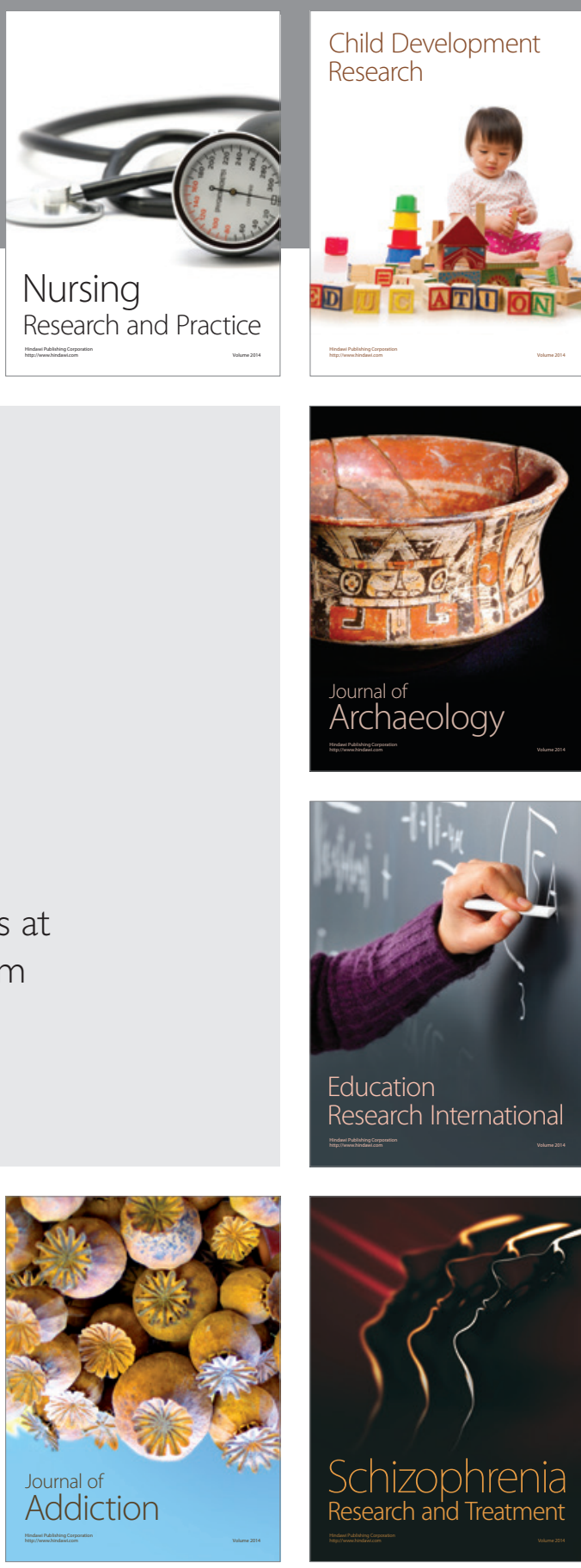

(D)
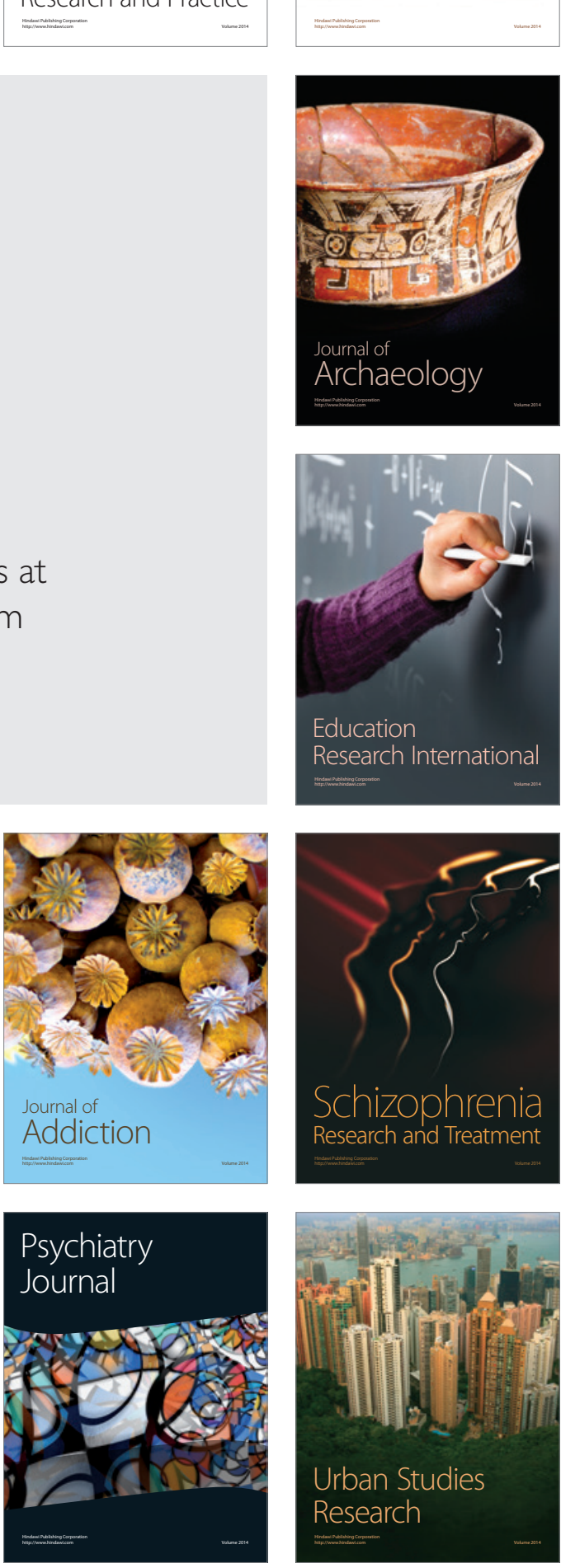